\title{
Surface Layer States of Worn Uncoated and TiN-Coated WC/Co-Cemented Carbide Cutting Tools after Dry Plain Turning of Carbon Steel
}

\author{
Johannes Kümmel, ${ }^{1}$ Katja Poser, ${ }^{1}$ Frederik Zanger, ${ }^{2}$ \\ Jürgen Michna, ${ }^{2}$ and Volker Schulze ${ }^{1,2}$ \\ ${ }^{1}$ Institute of Applied Materials (IAM-WK), Karlsruhe Institute of Technology (KIT), Kaiserstraße 12, 76131 Karlsruhe, Germany \\ ${ }^{2}$ Institute of Production Science (wbk), Karlsruhe Institute of Technology (KIT), Kaiserstraße 12, 76131 Karlsruhe, Germany \\ Correspondence should be addressed to Johannes Kümmel; johannes.kuemmel@kit.edu
}

Received 21 May 2012; Accepted 20 December 2012

Academic Editor: Meng Hua

Copyright ( $) 2013$ Johannes Kümmel et al. This is an open access article distributed under the Creative Commons Attribution License, which permits unrestricted use, distribution, and reproduction in any medium, provided the original work is properly cited.

\begin{abstract}
Analyzing wear mechanisms and developments of surface layers in WC/Co-cemented carbide cutting inserts is of great importance for metal-cutting manufacturing. By knowing relevant processes within the surface layers of cutting tools during machining the choice of machining parameters can be influenced to get less wear and high tool life of the cutting tool. Tool wear obviously influences tool life and surface integrity of the workpiece (residual stresses, surface quality, work hardening, etc.), so the choice of optimised process parameters is of great relevance. Vapour-deposited coatings on WC/Co-cemented carbide cutting inserts are known to improve machining performance and tool life, but the mechanisms behind these improvements are not fully understood. The interaction between commercial TiN-coated and uncoated WC/Co-cemented carbide cutting inserts and a normalised SAE 1045 steel workpiece was investigated during a dry plain turning operation with constant material removal under varied machining parameters. Tool wear was assessed by light-optical microscopy, scanning electron microscopy (SEM), and EDX analysis. The state of surface layer was investigated by metallographic sectioning. Microstructural changes and material transfer due to tribological processes in the cutting zone were examined by SEM and EDX analyses.
\end{abstract}

\section{Introduction}

At machining metals it is important to know about the wear behaviour of the cutting tool. This importance arises due to the fact that the surface integrity of the machined workpiece is influenced by tool wear $[1,2]$. In this case surface integrity is described by three main parameters: the surface roughness, the residual stress state, and the work hardening in the surface zone [1]. For further improvement in the knowledge of wear behaviour of cutting tools the surface layer states of the worn tools are important to distinguish between different wear mechanisms acting in the cutting zone. One possibility at investigating wear with respect to the applied cutting parameters (e.g., cutting speed, feed rate, and depth of cut) is the idea proposed by Lim and Ashby with the wear mechanism maps [3]. Here the most important aspects of wear (seizure, delamination wear, mild wear, severe wear, etc.) are displayed with respect to the parameters varied in the wear tests (sliding velocity, pressure, etc.). The wear map approach is also applied to metal machining, and therefore the wear is displayed as a function of cutting speed $v_{c}$ and feed rate $f[4$, 5]. In this work the aim is to develop a better understanding of the wear characteristics for different cutting parameters and different tool materials and to get therefore a deeper knowledge of the wear processes acting in the cutting zone. The surface layer states in the uncoated and in the TiNcoated cutting tool generated during the metal machining operation are mainly addressed. These surface layer states are important for the wear mechanisms that will lead to the degradation of the cutting tool. By knowing these surface 
TABLE 1: Chemical composition of workpiece material (SAE 1045) in weight \%.

\begin{tabular}{lccccccc}
\hline C & Si & Mn & P & S & Cr & Ni & Mo \\
\hline 0.420 & 0.285 & 0.663 & 0.021 & 0.035 & 0.153 & 0.107 & 0.021 \\
\hline
\end{tabular}

TABLE 2: Cutting parameter combinations used in cutting experiments for the uncoated tool (all values) and for the TiN coated tool (values marked with symbol ${ }^{*}$ ).

\begin{tabular}{|c|c|c|c|c|c|c|c|c|c|}
\hline Cutting speed $(\mathrm{m} / \mathrm{min})$ & $50^{*}$ & $100^{*}$ & 125 & $150^{*}$ & 100 & 100 & 100 & 100 & $100^{*}$ \\
\hline Feed rate $(\mathrm{mm} / \mathrm{rev})$ & $0.2^{*}$ & $0.2^{*}$ & 0.2 & $0.2^{*}$ & 0.1 & 0.15 & 0.25 & 0.3 & $0.5^{*}$ \\
\hline
\end{tabular}

layer states a knowledge based-metal cutting operation can be achieved. Nowadays some more complex coatings than TiN coatings are also used in the metal cutting of plain carbon steels (e.g., TiAlCN, AlCrN + TiAlCN coatings, etc.). For this examination the TiN-coating was used to have a better possibility of surface layer state characterisation by metallographic methods and the SEM examination [6].

\section{Experimental Setup}

For the experiments the chosen workpiece material was SAE 1045 plain carbon steel in a normalised state. The workpiece material had a ferritic-pearlitic microstructure with a mean grain size of ferrite and pearlite of $16 \mu \mathrm{m}$. The hardness of the steel was 194 HV1 measured by the Vickers hardness testing method. The chemical composition of the workpiece material is given in Table 1 .

The workpieces were cylinders with length $100 \mathrm{~mm}$ and diameter $58 \mathrm{~mm}$. The machining was done by dry plain turning down to a diameter of $24 \mathrm{~mm}$. The dry plain turning was performed with a machining centre Heller MC 16. The cutting tool used for the experiments was industrial fine-grained (grain size of WC is $0.5 \mu \mathrm{m}$ ) cemented carbide (K10) with a composition of 94 volume-\% WC and 6 volume- $\%$ Co in an uncoated state and in a TiN coated state. The TiN-coating (thickness $3 \mu \mathrm{m}$ ) was deposited directly on the cemented carbide substrate. The designation of the tool is SNMA 120408 according to the standard DIN ISO 1832 without any chip breakers to provide better wear measurement. The cutting tool has a square geometry and a wedge angle $\beta$ of $90^{\circ}$. The corner radius $r_{\varepsilon}$ is $0.8 \mathrm{~mm}$ and the cutting edge radius $r_{\beta}$ of the cutting tools is $30 \mu \mathrm{m}$. The entering angle between the main cutting edge and feed direction $\kappa_{r}$ is $45^{\circ}$, and the used clearance angle $\alpha$ was $7^{\circ}$ with a rake angle $\gamma$ of $-7^{\circ}$. The varied cutting parameters (cutting speed and feed rate) used in the experiments are shown in Table 2.

The wear measurements were conducted after different cutting lengths by light optical microscopy and according to the standard ISO Norm 3685 [7]. The examination of surface layer states was done by scanning electron microscopy (SEM) and chemical analysis by EDX. For further examination the cutting tools were sectioned in the worn zone by using a diamond wire saw for acquiring a metallographic section. These specimens were also examined by SEM and EDX analyses.

\section{Results}

3.1. Wear Examination of Uncoated Cutting Tools for Different Cutting Parameters. The wear was documented after different cutting lengths for the different cutting parameter combinations used, which were mentioned in Table 2. In Figure 1 there is a display of the wear evolution for the parameters $v_{c}=100 \mathrm{~m} / \mathrm{min}, f=0.25 \mathrm{~mm} / \mathrm{rev}$, and $a_{p}=0.1 \mathrm{~mm}$. The reason for the detailed examination of wear measurement is the proper determination of tool wear curves $[8,9]$ and to get the possibility to relate the wear of the cutting tool to the surface layer state in the resulting workpiece surface.

With an increasing cutting length the tool has an increasing crater wear depth and an increase in flank and notch wear. Another wear characteristic is the good adhesion between the workpiece material and the cutting tool. In Figure 1 the formation of built-up edges is visible and some built-up layer zones are shown. Those are present due to good adhesion tendency between steel and cemented carbide. Fragments of these built-up edges (or dead zones) which are described fundamentally in $[10,11]$ are visible also on the chip surface and on the workpiece surface. These layers cause relatively rough surfaces on the workpiece with a severely deformed microstructure. For the constant cutting speed of $100 \mathrm{~m} / \mathrm{min}$ the feed rate was varied according to Table 2 . The results of the wear measurement are shown in Figure 2. An increase in the wear intensity with increasing feed rate can be seen.

The same measurements were done for constant feed rate of $0.2 \mathrm{~mm} / \mathrm{rev}$ and varying cutting speed. The results are shown in Figure 3.

For varying cutting speed there is also a strong tendency to increase wear intensity with increasing cutting speed. For the cutting speed of $100 \mathrm{~m} / \mathrm{min}$ there is a slight minimum, considering the final state of the worn cutting tool after the same amount of material removal.

3.2. Wear Examination of TiN-Coated Cutting Tools. For the comparison of the uncoated and TiN-coated cutting tools four sets of parameters (feed rate and cutting speed) were chosen. These sets of parameters are also shown in Table 2 marked with the symbol ${ }^{*}$.

In Figure 4 a comparison of the wear of uncoated cutting tools and TiN-coated cutting tools is shown for one of the four parameter sets. It can be seen that the $\mathrm{TiN}$ coating is highly improving the wear behaviour of the cemented carbide cutting tools. During the cutting process there is no built-up 


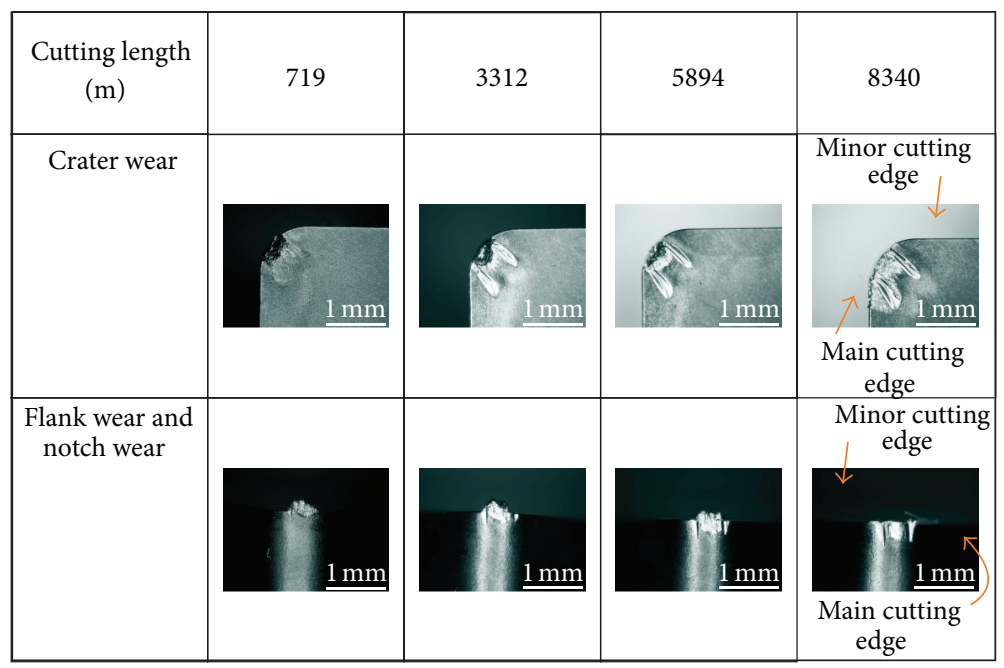

FIGURE 1: Overview of wear evolution for the cutting parameters $v_{c}=100 \mathrm{~m} / \mathrm{min}, f=0.25 \mathrm{~mm} / \mathrm{rev}$, and $a_{p}=0.1 \mathrm{~mm}$.

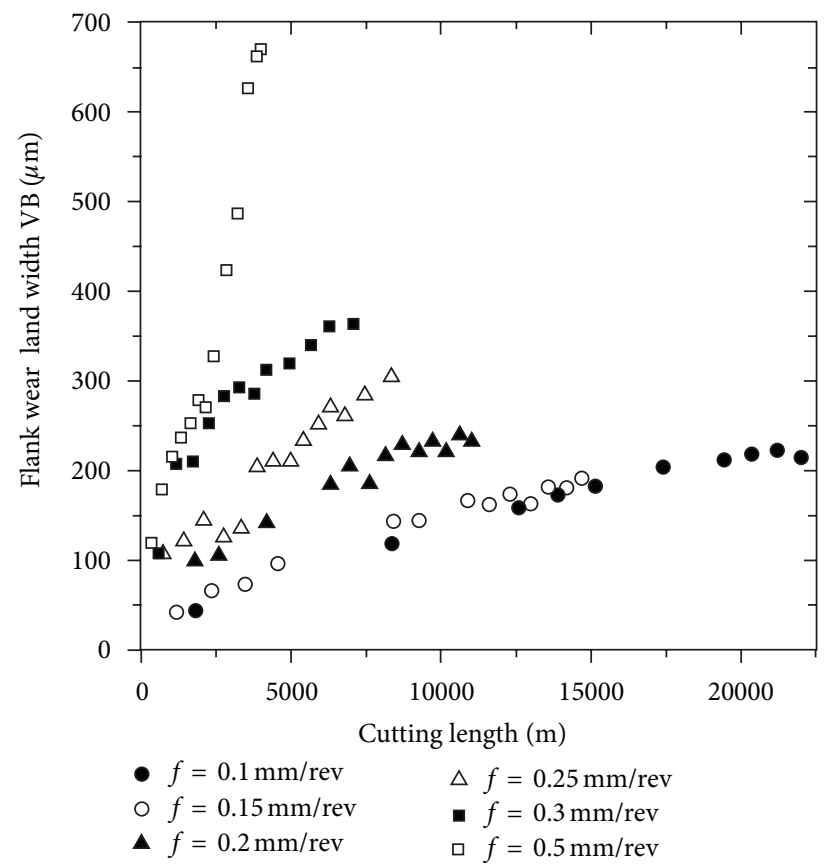

(a)

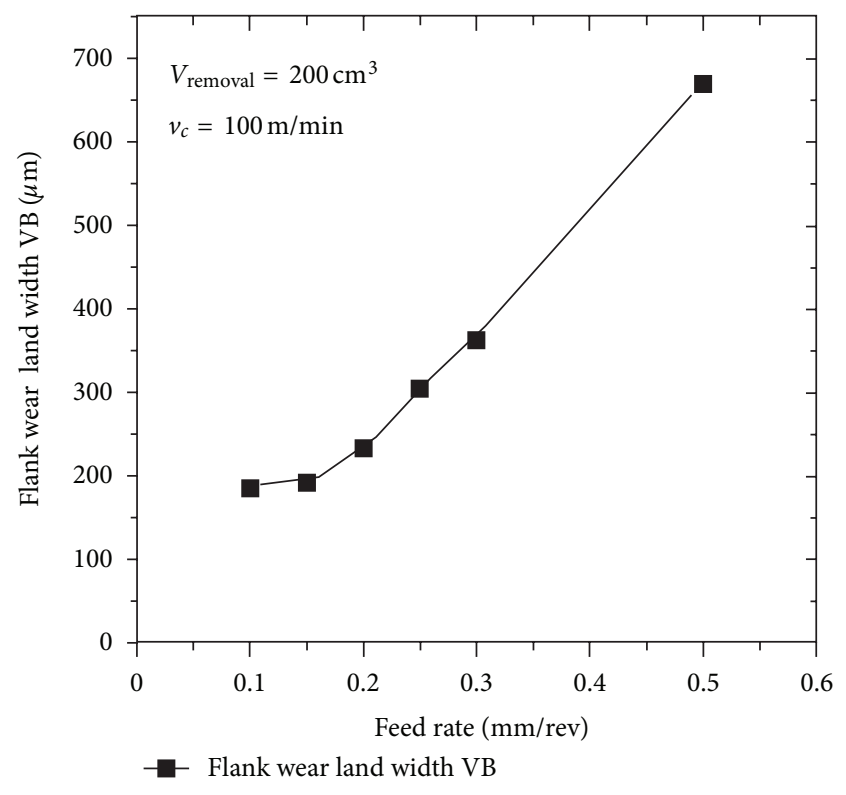

(b)

FIGURE 2: Flank wear land width VB measurement with respect to the cutting length for different feed rates $(0.1 \mathrm{~mm} / \mathrm{rev}-0.5 \mathrm{~mm} / \mathrm{rev})$ and comparison of the final state of tool wear after material removal of $200 \mathrm{~cm}^{3}$.

edge formation on the TiN-coated cutting tool, and the wear intensity is much smaller than for the uncoated cutting tool. For the TiN-coated tool there is only little wear visible in Figure 4.

The wear was also measured in the case of the TiN-coated cutting tool and is displayed in Figure 5 with respect to the cutting length, and the final wear states are also matched in a 3D-view of flank wear land width VB with regard to the cutting parameters: cutting speed and feed rate. From
Figure 5 one can clearly see that the TiN coating is highly improving the wear resistance for the cutting tool in dry plain turning application. Especially in the higher cutting speed regime $(150 \mathrm{~m} / \mathrm{min})$ for the own chosen cutting parameters the TiN coating improves wear behaviour to a great extent.

The dashed line "linear fit TiN" in Figure 5 is a linear regression line for the TiN-coated cutting tool used with the parameters $v_{c}=150 \mathrm{~m} / \mathrm{min}$ and $f=0.2 \mathrm{~mm} / \mathrm{rev}$. The solid line "linear fit WC/Co" in Figure 5 is a linear regression 


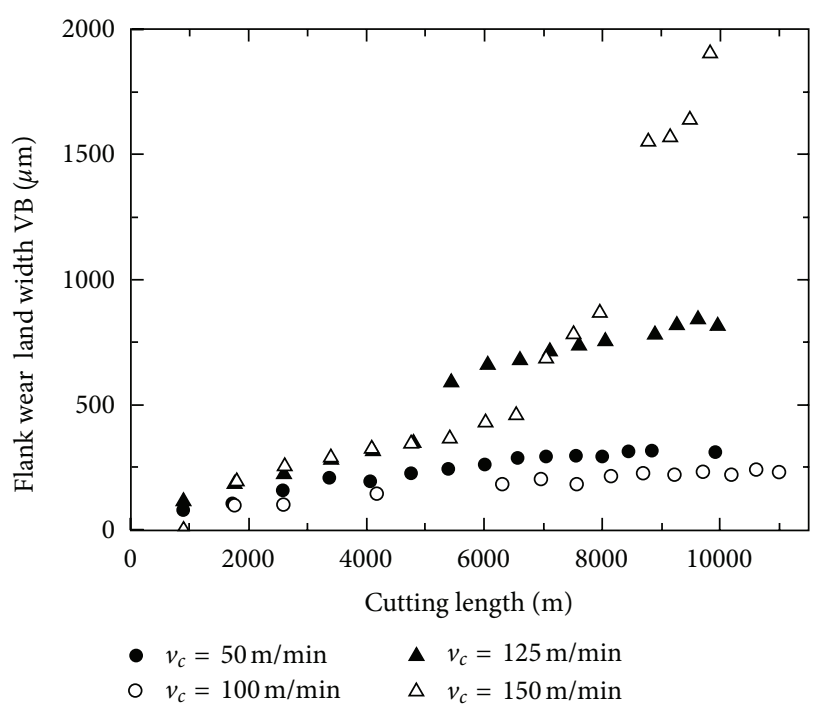

(a)

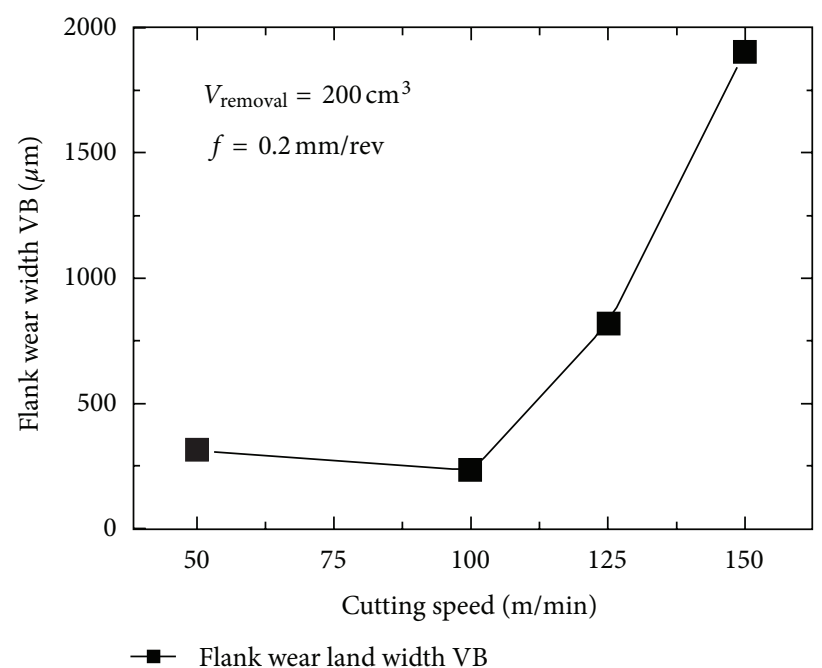

(b)

FIGURE 3: Flank wear land width VB with respect to cutting length (for varying cutting speed $50 \mathrm{~m} / \mathrm{min}-150 \mathrm{~m} / \mathrm{min}$ ) and constant feed rate and comparison of the final state of tool wear after material removal of $200 \mathrm{~cm}^{3}$.

\begin{tabular}{|c|c|c|c|c|}
\hline $\begin{array}{c}\text { Cutting length } \\
(\mathrm{m})\end{array}$ & 898 & 3405 & 5630 & 8155 \\
\hline $\begin{array}{c}\text { Flank and } \\
\text { notch wear } \\
\text { (uncoated) }\end{array}$ & $1 \mathrm{1 \textrm {mm }}$ & $\underline{1 \mathrm{~mm}}$ & $\underline{1 \mathrm{~mm}}$ & $\begin{array}{c}\text { Minor cutting } \\
/ \text { edge }\end{array}$ \\
$\begin{array}{c}\text { Main cutting } \\
\text { edge }\end{array}$ \\
\hline $\begin{array}{c}\text { Flank wear and } \\
\text { notch wear } \\
\text { (TiN coated) }\end{array}$
\end{tabular}

FIgURE 4: Comparison of wear of uncoated and TiN-coated cutting tools for set of parameter: $v_{c}=100 \mathrm{~m} / \mathrm{min}, f=0.20 \mathrm{~mm} / \mathrm{rev}$, and $a_{p}=0.1 \mathrm{~mm}$.

line for the linear wear regime up to a cutting length of $8000 \mathrm{~m}$ for the uncoated cutting tool used with the same parameters.

The examination of wear in the final state of the cutting process was also done by SEM. Two different states, one for a lower $(100 \mathrm{~m} / \mathrm{min})$ and one for a higher $(150 \mathrm{~m} / \mathrm{min})$ cutting speed, were examined.

In Figure 6 the surface structure of the worn rake face of the uncoated cutting tool is shown. In the crater wear region the most important wear mechanisms are the adhesion of workpiece material adhering to the rake face and tungsten carbide grain pullouts. This is due to the strong adhesion tendency of steel to the cemented carbide. This strong adhesive effect is also responsible for the formation of builtup edges. In comparison with Figure 6(a) the higher cutting speed applied during the metal cutting process leads to a smoother worn surface in the crater wear region which is seen in a higher magnification in Figure 6(b).

The rake face of the TiN-coated cutting tool that is shown in Figure 7 is less worn than for the uncoated cutting tool. Only in the region next to the cutting edge, where the highest intensity of chip flow is assumed, there are some areas without the TiN coating. In these parts of the rake face the cemented carbide substrate is visible. Further examination by energy dispersive X-ray spectroscopy (EDX) on the rake face gives some chemical information of the worn surface. In Figure 8 there is a picture shown from the rake face with a delaminated TiN-coating structure and an EDX line scan showing the chemical analysis across the worn surface. In the brighter region of the worn tool (WC/Co substrate) there is 

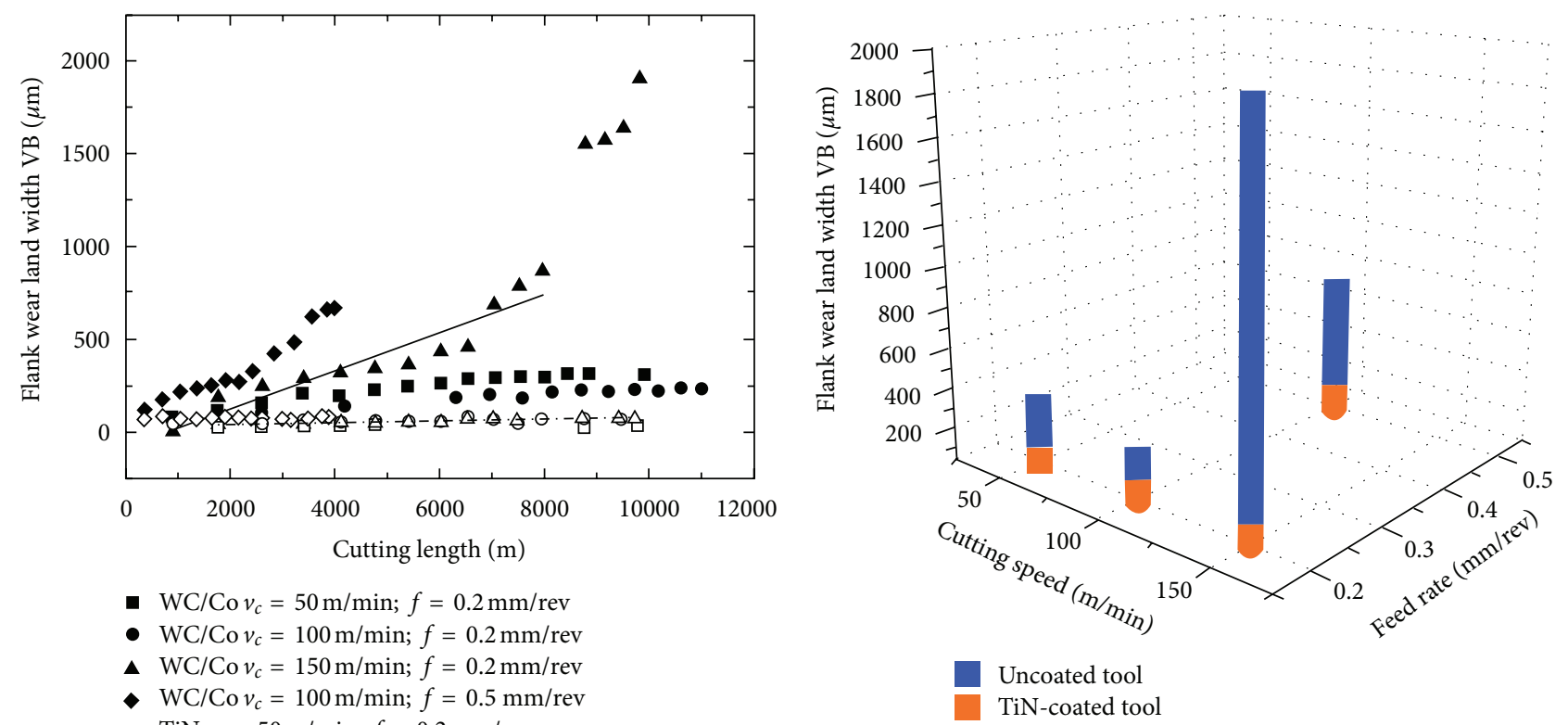

- $\mathrm{WC} / \operatorname{Co} v_{c}=50 \mathrm{~m} / \mathrm{min} ; f=0.2 \mathrm{~mm} / \mathrm{rev}$

- $\mathrm{WC} / \operatorname{Co} v_{c}=100 \mathrm{~m} / \mathrm{min} ; f=0.2 \mathrm{~mm} / \mathrm{rev}$

- $\mathrm{WC} / \operatorname{Co} v_{c}=150 \mathrm{~m} / \mathrm{min} ; f=0.2 \mathrm{~mm} / \mathrm{rev}$

- WC/Co $v_{c}=100 \mathrm{~m} / \mathrm{min} ; f=0.5 \mathrm{~mm} / \mathrm{rev}$

口 $\operatorname{TiN} v_{c}=50 \mathrm{~m} / \mathrm{min} ; f=0.2 \mathrm{~mm} / \mathrm{rev}$

○ $\operatorname{TiN} v_{c}=100 \mathrm{~m} / \mathrm{min} ; f=0.2 \mathrm{~mm} / \mathrm{rev}$

$\Delta \operatorname{TiN} v_{c}=150 \mathrm{~m} / \mathrm{min} ; f=0.2 \mathrm{~mm} / \mathrm{rev}$

$\diamond \operatorname{TiN} v_{c}=100 \mathrm{~m} / \mathrm{min} ; f=0.5 \mathrm{~mm} / \mathrm{rev}$

— Linear fit WC/Co

...- Linear fit TiN

FIGURE 5: Comparison of flank wear land width VB with respect to the cutting length for the uncoated (black closed symbols) and TiN-coated (open symbols) cutting tool. The diagram on the right side shows a comparison (uncoated versus coated cutting tool) of the flank wear land width VB in the final state of the cutting tool with respect to cutting speed and feed rate.

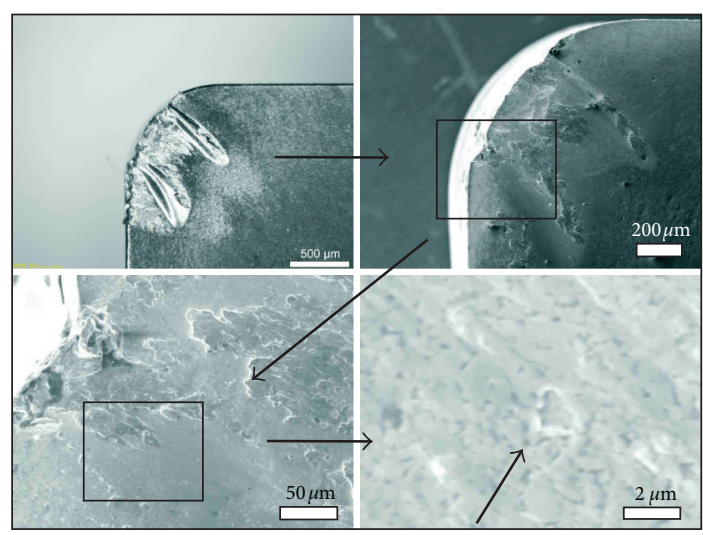

(a)

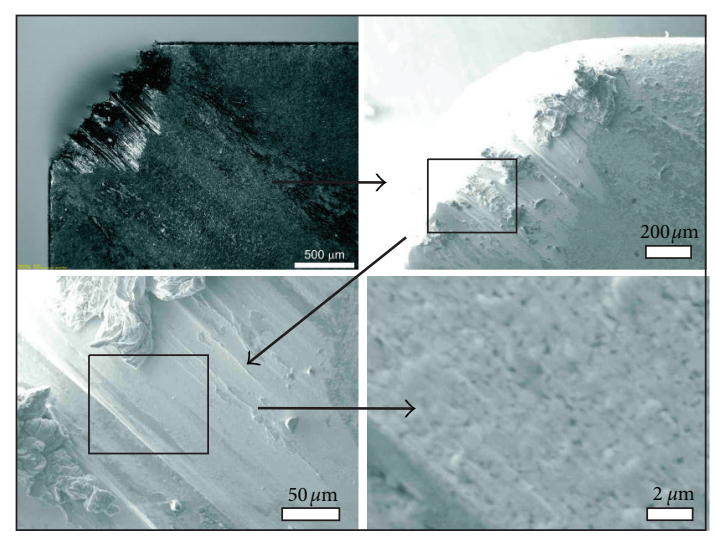

(b)

FIGURE 6: SEM examination of worn rake face of uncoated cutting tools. In (a) the crater wear is visible for the cutting parameters $v_{c}=100 \mathrm{~m} / \mathrm{min}, f=0.25 \mathrm{~mm} / \mathrm{rev}$, and $a_{p}=0.1 \mathrm{~mm}$. In the highest magnification there is a WC-grain pullout visible on the rake face. On the right (b) there is a SEM examination of worn rake face of uncoated cutting tool with $v_{c}=150 \mathrm{~m} / \mathrm{min}, f=0.20 \mathrm{~mm} / \mathrm{rev}$, and $a_{p}=0.1 \mathrm{~mm}$.

a strong tendency of Fe adhesion from the workpiece (peaks of high intensity of Fe). The TiN-coated areas (darker parts in Figure 8(a)) show no such intensive Fe peaks in the EDX spectrum. Therefore, the adhesion of iron to the TiN coating is less strong.
In Figure 8(b) two important intensity curves obtained from an EDX line scan are shown. The black closed symbols denote the titanium peak intensity and the open symbols denote the intensity of Fe. In the region without TiN coating there are high intensities from $\mathrm{Fe}$, showing strong adhesion 


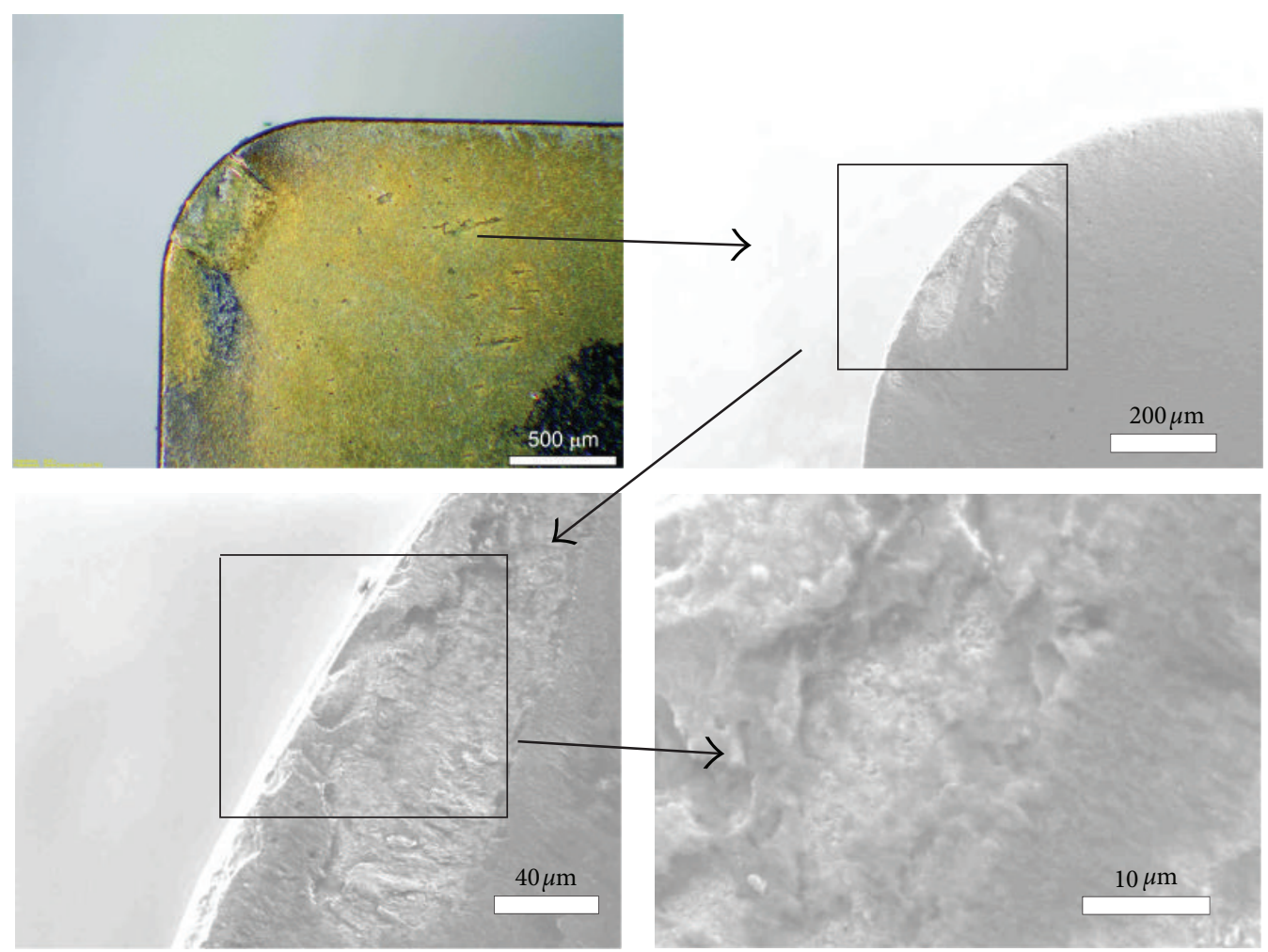

FIGURE 7: SEM examination of worn rake face of TiN-coated cutting tool: $v_{c}=150 \mathrm{~m} / \mathrm{min}, f=0.20 \mathrm{~mm} / \mathrm{rev}$, and $a_{p}=0.1 \mathrm{~mm}$.

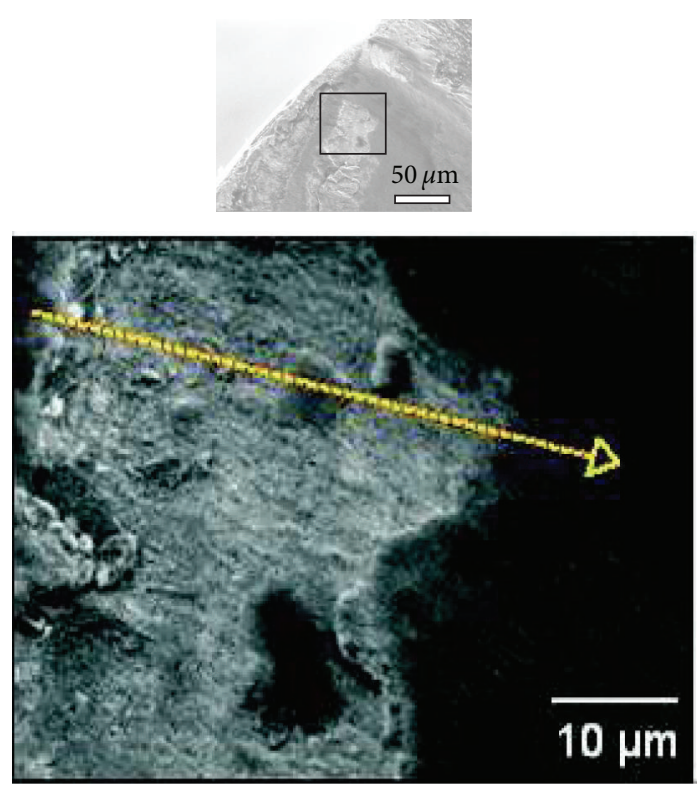

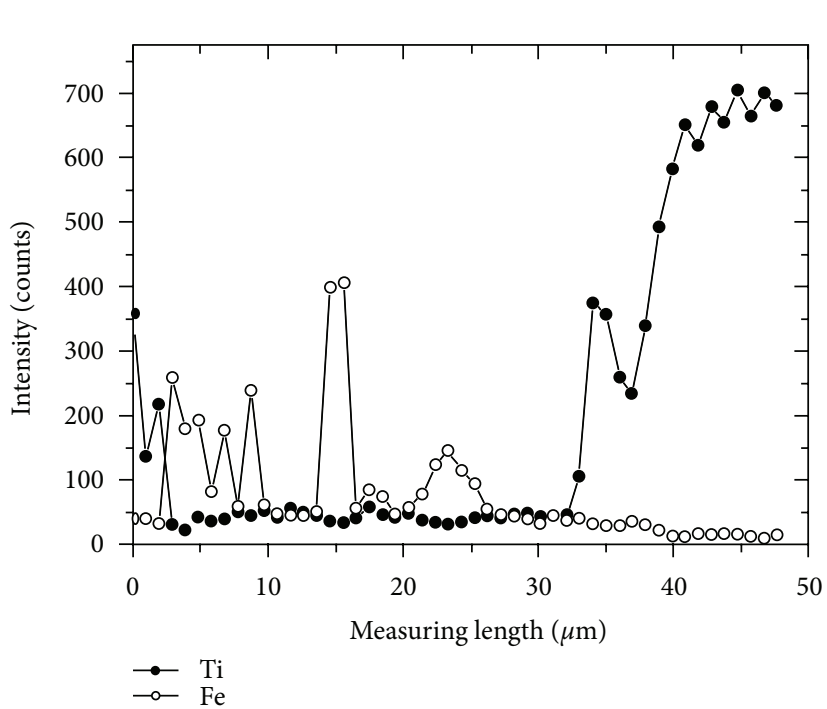

(b)

Figure 8: (a) SEM image worn rake face of TiN-coated cutting tool: $v_{c}=150 \mathrm{~m} / \mathrm{min}, f=0.20 \mathrm{~mm} / \mathrm{rev}$, and $a_{p}=0.1 \mathrm{~mm}$. The arrow depicts the path of the EDX line scan shown in (b). 


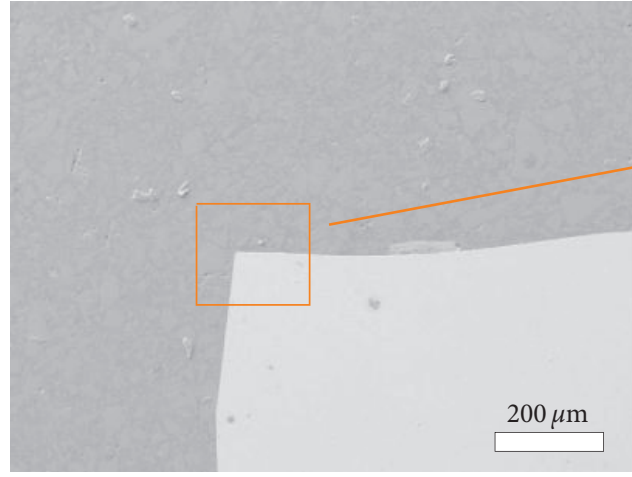

(a)

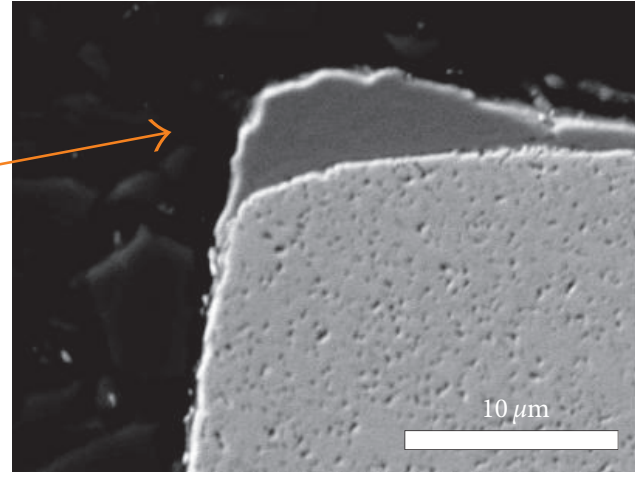

(b)

FIGURE 9: SEM picture of worn uncoated cutting tool in final state (after cutting length of $7084 \mathrm{~m}$ ) with cutting parameters as follows: $v_{c}=100 \mathrm{~m} / \mathrm{min}, f=0.30 \mathrm{~mm} / \mathrm{rev}$, and $a_{p}=0.1 \mathrm{~mm}$. Due to the high temperatures acting in the cutting zone some evidence is seen for plastic lowering of the cutting edge [9].

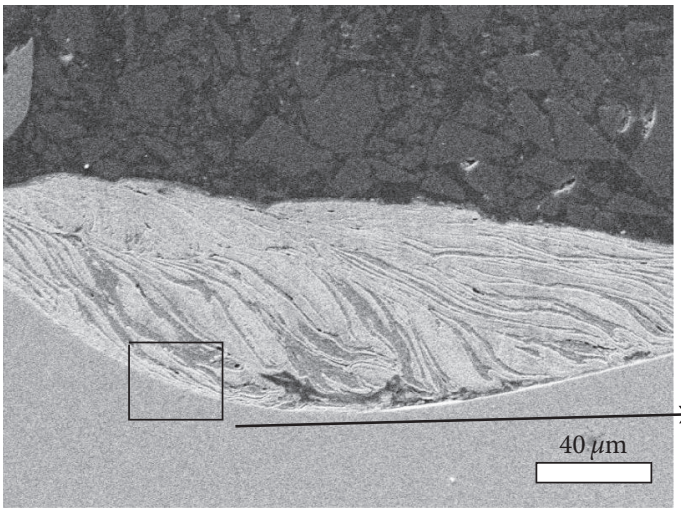

(a)

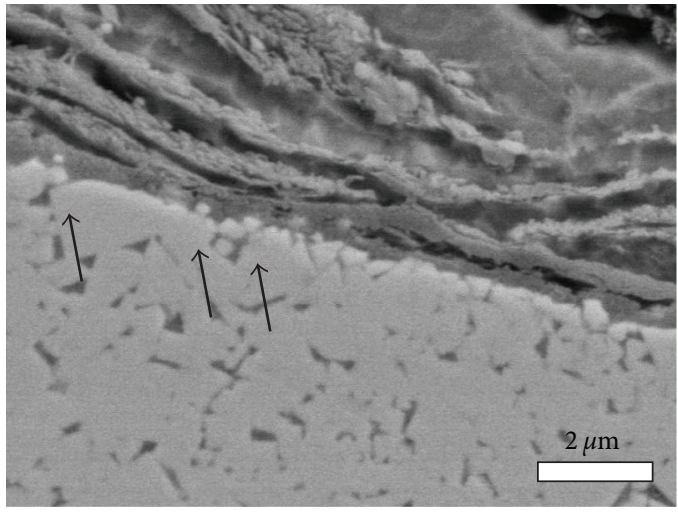

(b)

FIGURE 10: SEM picture of worn uncoated cutting tool in final state (after cutting length of $14669 \mathrm{~m}$ ) with cutting parameters as follows: $v_{c}=100 \mathrm{~m} / \mathrm{min}, f=0.15 \mathrm{~mm} / \mathrm{rev}$, and $a_{p}=0.1 \mathrm{~mm}$.

of workpiece material on the rake face, because of the worn TiN coating.

\subsection{Examination of Surface Layer States in Uncoated and} TiN-Coated Cutting Tool. For the examination of the surface layer states in the cutting tool metallographic sectioning was done [6], where the worn tool is carefully cut by the use of a diamond wire saw and is prepared by metallographic methods. The sectioned worn cutting tool was embedded in a thermoset resin for metallographic grinding and polishing. Some examples of metallographic sections prepared this way are shown in Figures 9 and 10.

In Figure 9 an overview of a worn WC-Co cemented carbide cutting tool in uncoated state is shown with a built-up edge on the cutting edge. In the metallographic sections the crater wear, flank wear and material transfer from the work piece can be detected.

In Figure 10 the worn surface state is shown, and with the aid of the back scatter electron detector (BSE) some little WC-grain fragments are visible in the interface between the built-up layer and the uncoated cutting tool. Concerning the wear mechanisms acting for the uncoated cutting tool, microcracking of WC grains is found. These small particles cause abrasive wear due to their hardness. This abrasive wear is caused by the small wear debris in the interfacial area.

The same procedure for the examination of cutting tool surface layer states of TiN-coated cutting tools was applied for the cutting parameter set $v_{c}=100 \mathrm{~m} / \mathrm{min}, f=0.5 \mathrm{~mm} / \mathrm{rev}$, and $a_{p}=0.1 \mathrm{~mm}$.

In Figure 9(a) the flank wear and crater wear are both visible. On the right side in Figure 9(b) there is a detailed picture showing the built-up edge in a higher magnification.

In Figure 10(a) the crater wear is visible with a large built-up layer of work material. In Figure 10(b) the interface between the cemented carbide substrate and the etched SAE 1045 built-up layer is shown (etching agent: Nital).

In Figure 11 it is shown that the TiN coating has a protective effect on the wear behaviour of the cutting tool. Only locally there are some workpiece fragments adhering on the cutting tool substrate, where the TiN coating is worn, and the cemented carbide substrate is exposed to the workpiece material. 


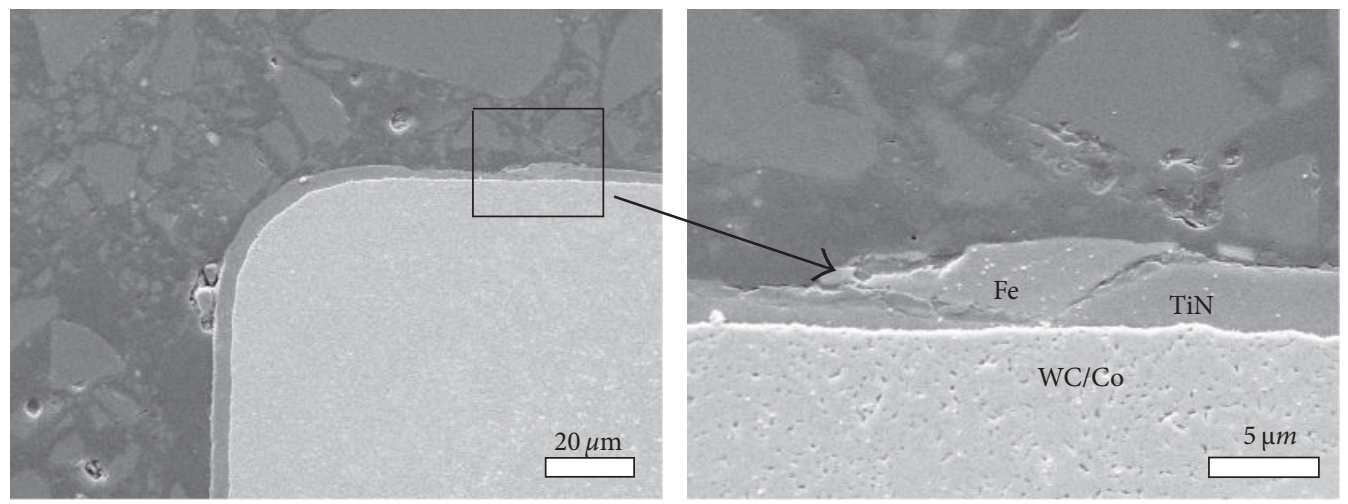

FIGURE 11: SEM picture of slightly worn TiN-coated cutting tool in final state with cutting parameters as follows: $v_{c}=100 \mathrm{~m} / \mathrm{min}$, $f=0.5 \mathrm{~mm} / \mathrm{rev}$, and $a_{p}=0.1 \mathrm{~mm}$. The cutting edge is shown, and on the right hand side the detail is shown, with a piece of workpiece material adhering to the WC/Co substrate.

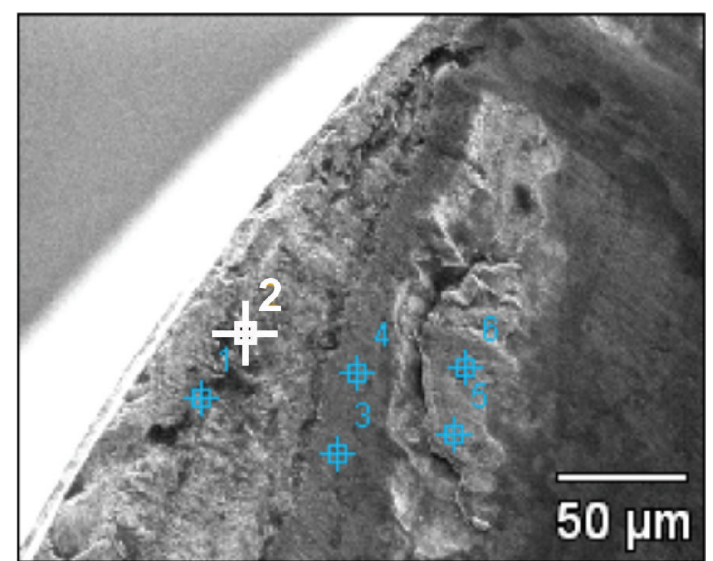

(a)

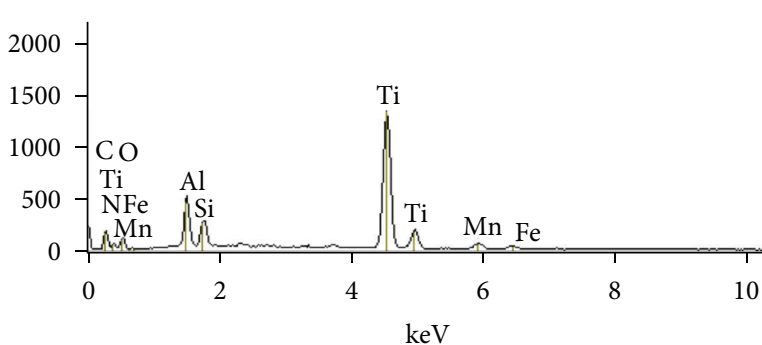

(b)

FIGURE 12: EDX spectrum on rake face of a worn TiN-coated cutting tool for point 2 near the cutting edge. Some elements from the workpiece material were found (cutting conditions: $v_{c}=150 \mathrm{~m} / \mathrm{min}, f=0.2 \mathrm{~mm} / \mathrm{rev}$, and $a_{p}=0.1 \mathrm{~mm}$ ).

\section{Discussion}

The examination of surface layer states of uncoated WC/Cocutting tools is one important aim of this paper. The main wear mechanisms for all chosen parameters in Table 2 are adhesive wear and a three-body abrasive wear for the uncoated cutting tool. The adhesive and three-body abrasive wear was also shown in further studies [12]. Other wear mechanisms like diffusion are also possible [13, 14]. The morphology of crater wear on the rake face for lower cutting speeds and feed rates, as seen in Figure 6, can be explained by the chip side flow because of small cutting depth chosen in the experiments. The chips show a curled structure, so that they can produce notch-like crater wear.

The examination of surface layer states in the TiNcoated cutting tool is another important aim of this paper. From Figure 5 it can be seen that the TiN coating is highly improving the wear behaviour of cemented carbide cutting tools. The wear intensity is reduced in the highest cutting speed regime by a factor of 20 due to the TiN coating for the comparison of the highest cutting speed of $150 \mathrm{~m} / \mathrm{min}$ in the linear wear regime in Figure 5 (the wear intensities as flank wear land width VB per cutting length were calculated by linear regression of the flank wear distribution in Figure 5). This can be explained by different reasons. TiN has got a higher hardness (2300 HV0.05 [15]) than cemented carbide (fine-grained cemented carbide 94 volume-\% WC, 6 volume$\%$ Co (1850 HV30) [16]). The thermal conductivity of TiN is lower $\left(29 \mathrm{Wm}^{-1} \mathrm{~K}^{-1}\right.$ [16]) than that of cemented carbide $\left(68.9 \mathrm{Wm}^{-1} \mathrm{~K}^{-1}[16]\right)$. Therefore, more heat will be conducted through the chip and the work piece material, and the TiNcoated cutting tool will see lower temperatures.

The most important difference between the wear behaviour of uncoated and TiN-coated tools is, however, the adhesion between workpiece and tool. In the case of steel workpieces, this adhesion to cemented carbide substrate is much stronger than to TiN coating. The adhesive wear is correlated to the atomic bonding of the different materials 


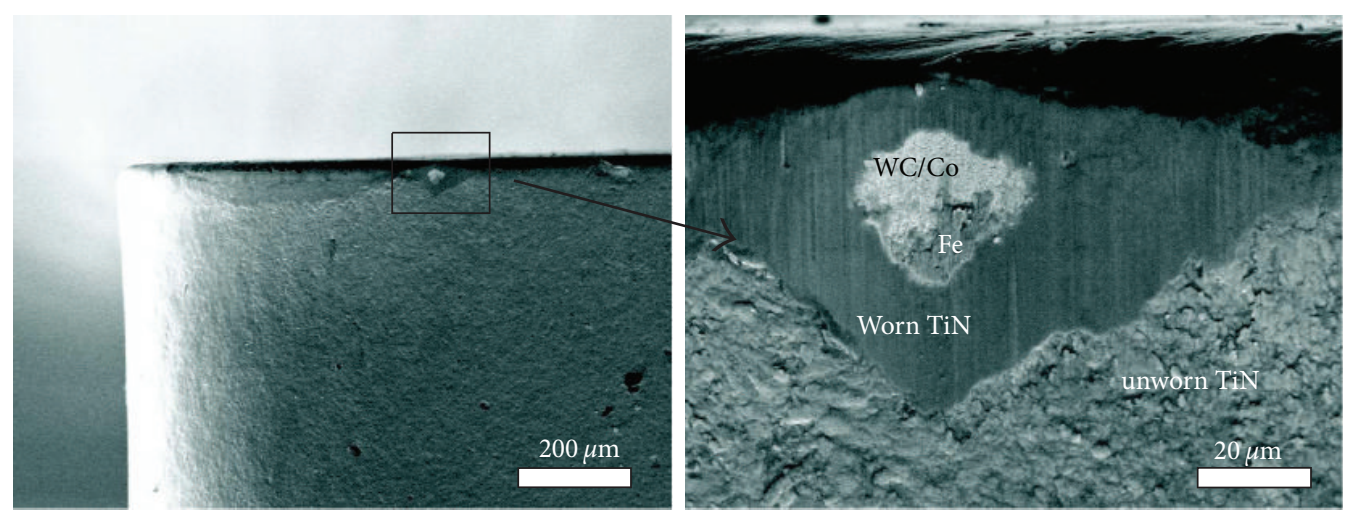

Figure 13: Small region of flank wear (resp. notch wear) of TiN-coated cutting tool, which was used under the cutting conditions of $v_{c}=100 \mathrm{~m} / \mathrm{min}, f=0.5 \mathrm{~mm} / \mathrm{rev}$, and $a_{p}=0.1 \mathrm{~mm}$.

between the different atoms of the workpiece material, and the cutting tool material and a smooth surface is necessary [17]. The different wear mechanisms acting in the cutting zone are abrasion and adhesion.

As shown, there is less-adhesive effect of the work material on the TiN coating. The wear mechanisms acting, when turning with a TiN-coated tool, were not examined in detail. There are some further possible reasons, why TiN has got a better wear behaviour. Some protective adhesion layers were found or assumed on TiN and AlCrN coatings $[6,18]$. On the worn TiN-layers some elements (Al, Si, etc., see Table 1) from the workpiece material were found (see Figure 12). These could also form a protective tribolayer during the cutting process.

The TiN coating changes its surface structure from a rougher surface to a smoother surface during the metal cutting process which can be attributed to the wear of chip flow respectively, the tool-workpiece interaction (see Figure 13). In Figure 13 the worn region of the TiN coating has got a smoother surface structure than the unworn TiNcoating.

In Figure 13, a small part of the flank face is shown where some notch wear is detected via SEM. There are three main parts of the cutting tool region: the surrounding part is consisting of unworn TiN coating. This as-deposited coating has got a rougher surface structure than the worn part of the tool, where sliding between chip/workpiece and the tool occurs. Here the sliding process leads to a smoothening of the TiN coating. In the middle of the worn region, the coating is fully worn. Cemented carbide substrate can be seen (brighter area in Figure 13), and adhering workpiece material (Fe) can be detected. This notch wear can be attributed to the high wear intensity that is acting at the beginning of the cutting process, when the cutting edge enters the workpiece.

\section{Conclusions/Summary}

An increasing load (higher feed rate or higher cutting speed) subjected to the cutting tool results in an increasing wear rate with respect to flank wear.
The formation of built-up edges, built-up layers, and dead zones is detected for the uncoated cemented carbide cutting tool. The reason for that is a strong adhesion of steel (workpiece material) to the cemented carbide.

The wear was examined by metallographic sectioning, and it was revealed that the wear mechanisms are adhesion and abrasion.

Improving wear behaviour of the TiN-coated cemented carbide cutting tools is due to the low adhesion of the selected workpiece material (SAE 1045) to the TiN coating. Hence there is no built-up edge or built-up layer formation on the TiN coating. On delaminated, respectively, fully worn TiN coating there is again a strong adhesion detected to the cemented carbide substrate, and a local increase in wear rate is observed.

\section{Acknowledgment}

The authors gratefully acknowledge the company OC Oerlikon Balzers for the deposition of the TiN coating.

\section{References}

[1] I. S. Jawahir, E. Brinksmeier, R. M'Saoubi et al., "Surface integrity in material removal processes: recent advances," CIRP Annals-Manufacturing Technology, vol. 60, no. 2, pp. 603-626, 2011.

[2] Q. Xie, A. E. Bayoumi, and L. A. Kendall, "On tool wear and its effect on machined surface integrity," Journal of Materials Shaping Technology, vol. 8, no. 4, pp. 255-265, 1990.

[3] S. C. Lim and M. F. Ashby, "Wear-mechanism maps," Acta Metallurgica, vol. 35, no. 1, pp. 1-24, 1987.

[4] S. C. Lim, Y. B. Liu, S. H. Lee, and K. H. W. Seah, "Mapping the wear of some cutting-tool materials," Wear, vol. 162-164, pp. 971-974, 1993.

[5] S. C. Lim, "Recent developments in wear-mechanism maps," Tribology International, vol. 31, no. 1-3, pp. 87-97, 1998.

[6] S. Karagöz and H. F. Fischmeister, "Metallographic observations on the wear process of TiN-coated cutting tools," Surface and Coatings Technology, vol. 81, no. 2-3, pp. 190-200, 1996. 
[7] "ISO 3685: tool-life testing with single-point turning tools," 1993.

[8] V. P. Astakhov, Tribology of Metal Cutting, vol. 52 of Tribology and Interface Engineering Series, Elsevier, 2006.

[9] V. P. Astakhov, “The assessment of cutting tool wear," International Journal of Machine Tools and Manufacture, vol. 44, no. 6, pp. 637-647, 2004.

[10] S. Jacobson and P. Wallén, "A new classification system for dead zones in metal cutting," International Journal of Machine Tool Design and Research, vol. 28, no. 4, pp. 529-538, 1988.

[11] P. K. Philip, "Built-up edge phenomenon in machining steel with carbide," International Journal of Machine Tool Design and Research, vol. 11, no. 2, pp. 121-132, 1971.

[12] H. Opitz and M. Gappisch, "Some recent research on the wear behaviour of carbide cutting tools," International Journal of Machine Tool Design and Research, vol. 2, no. 1, pp. 43-73, 1962.

[13] J. A. Arsecularatne, L. C. Zhang, and C. Montross, "Wear and tool life of tungsten carbide, PCBN and PCD cutting tools," International Journal of Machine Tools and Manufacture, vol. 46, no. 5, pp. 482-491, 2006.

[14] H. O. Gekonde and S. V. Subramanian, "Tribology of toolchip interface and tool wear mechanisms," Surface and Coatings Technology, vol. 149, no. 2-3, pp. 151-160, 2002.

[15] “Oerlikon Balzers product information BALINIT A," 2011.

[16] "Springer Materials: the Landolt Börnstein database, the worlds largest resource for physical and chemical data," 2009.

[17] Valentin L. Popov, Kontaktmechanik und Reibung: Von der Nanotribologie bis zur Erdbebendynamik, Springer, Berlin, Germany, 2010.

[18] J. Gerth, M. Larsson, U. Wiklund, F. Riddar, and S. Hogmark, "On the wear of PVD-coated HSS hobs in dry gear cutting," Wear, vol. 266, no. 3-4, pp. 444-452, 2009. 

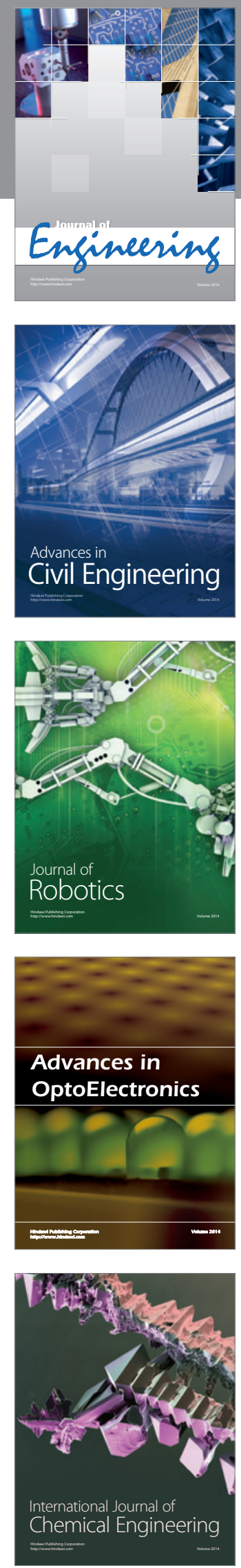

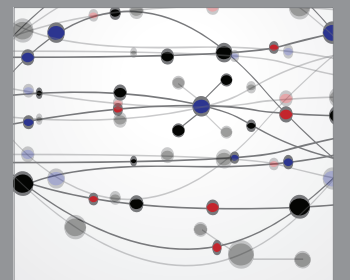

The Scientific World Journal
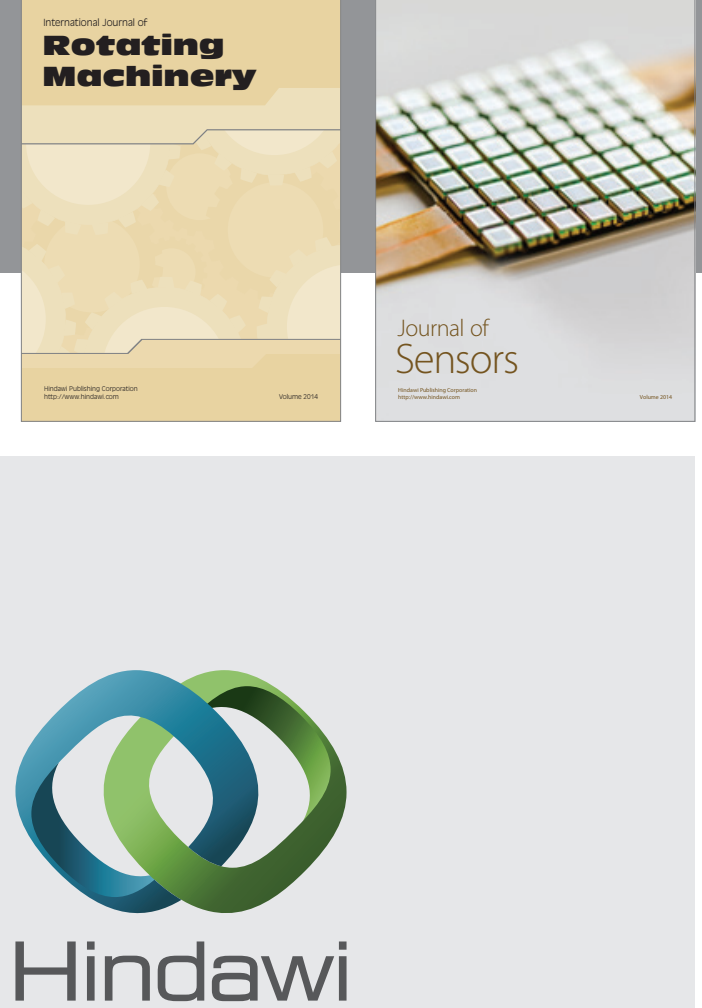

Submit your manuscripts at http://www.hindawi.com
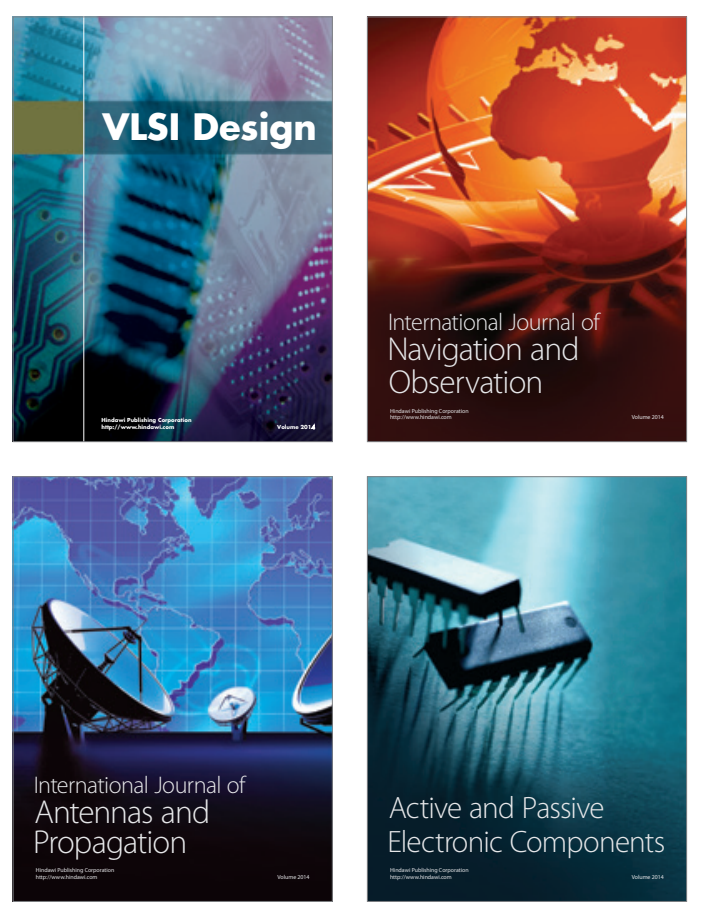
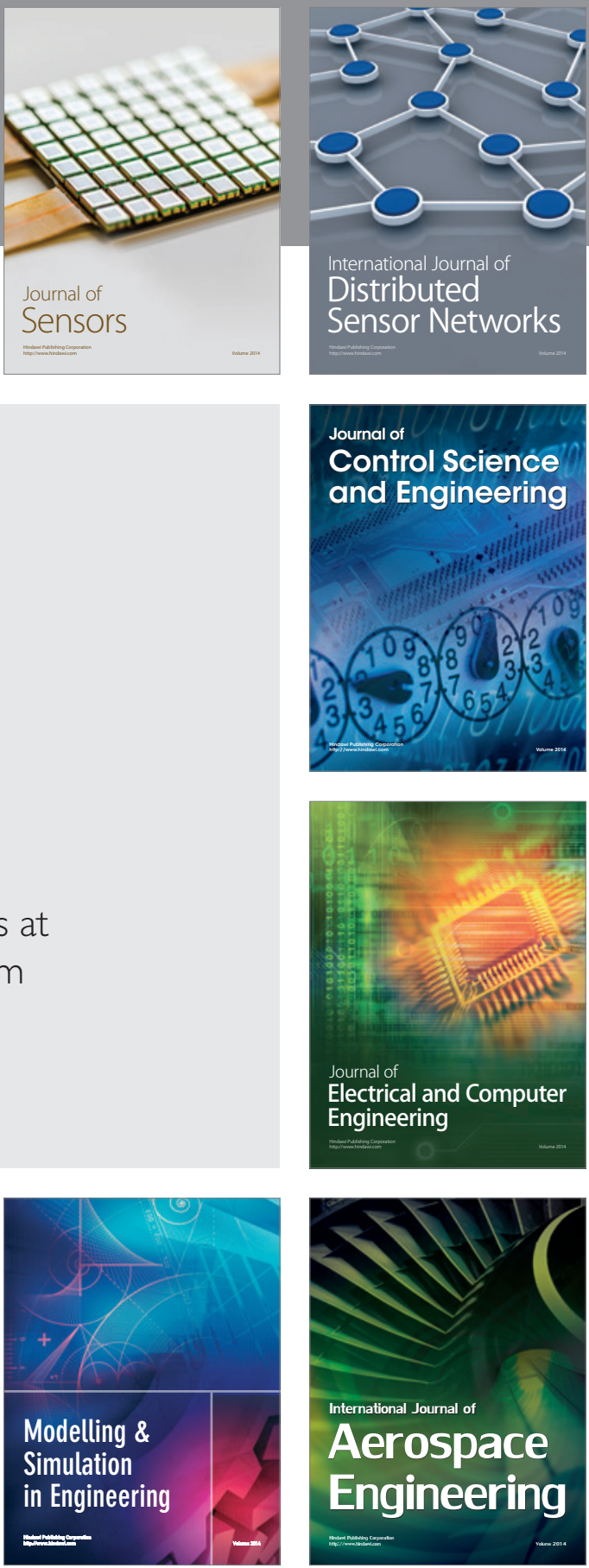

Journal of

Control Science

and Engineering
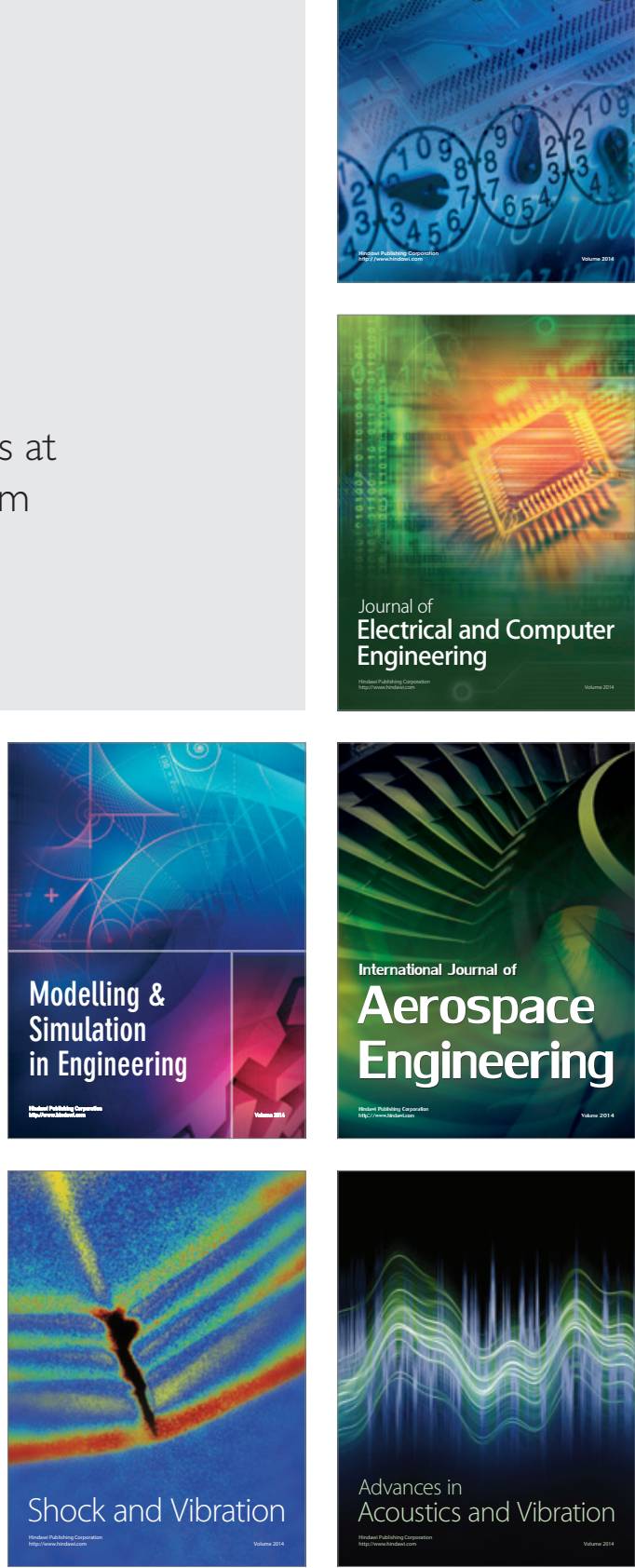